\title{
Relationship between Epicardial Fat Tissue Thickness and CRP and Neutrophil-Lymphocyte Ratio in Metabolic Syndrome Patients Over 65 Years
}

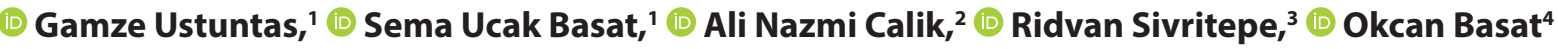 \\ 'Department of Internal Medicine, University of Health Sciences Turkey Umraniye Training and Research Hospital, Istanbul, Turkey \\ ${ }^{2}$ Department of Cardiology, University of Health Sciences Turkey Siyami Ersek Training and Research Hospital, Istanbul, Turkey \\ ${ }^{3}$ Department of Internal Medicine, Istanbul Medipol University Faculty of Medicine, Istanbul, Turkey \\ ${ }^{4}$ Department of Family Medicine, University of Health Sciences Turkey Gaziosmanpaşa Taksim Training and Research Hospital, Istanbul, Turkey
}

\begin{abstract}
Objective: There are no data evaluating the association of neutrophil-to-lymphocyte ratio (NLR) and C-reactive protein (CRP) with epicardial fat tissue thickness (EFTT) in elderly metabolic syndrome (MS) patients. In this study, we aimed to investigate the relationship of EFTT with CRP and NLR in patients with MS over 65 years.

Methods: A cross-sectional study was performed. Fifty patients (patient group) with MS and 25 subjects (control group) without MS were allocated in the study. All parameters were compared in patient and control groups. The correlations between NLR, CRP, and EFTT were evaluated.

Results: White blood cell and neutrophil levels were higher in MS group ( $p=0.020$ and $p=0.019$, respectively). Both transverse and longitudinal EFTT were increased in MS patients $(p<0.001)$. There was a significant correlation between the EFTT and NLR but not with CRP in the MS group $(r=0.4, p=0.003)$.

Conclusion: Our study showed that both longitudinal and transverse EFTT are associated with NLR in patients older than 65 years with MS. In geriatric MS patients, higher NLR level may be an indicator of increased visceral fat around the myocardium.

Keywords: Elderly; epicardial fat tissue; metabolic syndrome; neutrophil-to-lymphocyte ratio.

Please cite this article as: Ustuntas G, Basat SU, Calik AN, Sivritepe R, Basat O. Relationship between Epicardial Fat Tissue Thickness and CRP and Neutrophil-Lymphocyte Ratio in Metabolic Syndrome Patients Over 65 Years. Med Bull Sisli Etfal Hosp 2021;55(3):405-411.
\end{abstract}

\section{Introduction}

Epicardial fat tissue (EFT) is considered to be the indicator of visceral fat tissue surrounding myocardium. ${ }^{[1-4]}$ In the development of atherosclerosis in coronary arteries; EFT plays an active role by its local and paracrine effects. Similarly, EFT has been shown to be increased in patients with metabolic syndrome (MS) and obesity compared to the normal population. Therefore, EFT contributes to the development of insulin resistance and coronary artery disease by increasing

Address for correspondence: Rıdvan Sivritepe Asst. Prof. Department of Internal Medicine, Istanbul Medipol University Faculty of Medicine, Pendik Hospital, Adnan Menderes Boulevard No: 31-33 Pendik Istanbul/Turkey

Phone: +90 02164136300 E-mail: dr.ridvansivritepe@gmail.com

Submitted Date: January 27, 2021 Accepted Date: April 07, 2021 Available Online Date: September 24, 2021

${ }^{\circ}$ Copyright 2021 by The Medical Bulletin of Sisli Etfal Hospital - Available online at www.sislietfaltip.org

OPEN ACCESS This is an open access article under the CC BY-NC license (http://creativecommons.org/licenses/by-nc/4.0/). 
inflammation in MS patients. ${ }^{[5,6]}$ In some prospective studies, it has been indicated that high C-reactive protein (CRP) levels are significant risk factor for the development of chronic disease such as diabetes or hypertension, which are known to be components of MS. ${ }^{[7,8]}$

There is a significant independent relationship between inflammation markers such as leucocyte count, neutrophil count, CRP, interleukin, and TNF-a. ${ }^{[9,10]}$ In addition, neutrophil-to-lymphocyte ratio (NLR) is considered to be a marker of subclinical inflammation which is associated with morbidity and mortality in diabetic patients. ${ }^{[11,12]}$

Recent studies indicate to an association between NLR and MS, subsequently raising question on importance of inflammatory processes involving EFT and NLR in MS. ${ }^{[13]}$

There are no studies evaluating the association of NLR and CRP with EFT in elderly MS patients. In this study, we aimed to determine the relationship of EFT with CRP and NLR in patients with MS over 65 years.

\section{Material and Methods}

The study was approved by the local ethics committee (The Ethics Committee of University of Health Sciences Umraniye Education and Research Hospital, Date: 15.12.2016; Number: B.10.1.TKH.4.34.H.GP.0.01/128) and performed according to the Declaration of Helsinki principles. All subjects gave informed consent. Patients were recruited among patients admitted to the internal medicine department of University of Health Sciences Umraniye Education and Research Hospital for general control. A total number of 75 subjects were included in the study. The number of the study participants was based on the power analysis. The patient group was consisted of 50 patients with MS over 65 years. The control group consisted of 25 healthy hospital staff, was similar in age and gender.

Patients aged $65-80$ years diagnosed with MS, who have normal kidney (GLOMERULAR filtration rate $>90 \mathrm{ml} /$ $\mathrm{dk} / 1.73 \mathrm{~m}^{2}$ ) and liver functions (alanine aminotransferase $<45 \mathrm{U} / \mathrm{L}$ and aspartate transferase $<34 \mathrm{U} / \mathrm{L}$ ) and who perform regular physical activities and adopt normal lifestyle were included in the study. Patients with documented diseases involving heart failure, atherosclerotic cardiovascular disease, structural heart disease, peripheric arteries disease, liver failure, acute and chronic kidney disease, chronic lung disease, thromboembolic disease, autoimmune vasculitis, malignancy, thyroid and autoimmune system, infections, and chronic usage of anti-inflammatory and/or immune suppressive medication were excluded from the study. Height was measured using a stadiometer (Ekoter mechanical stadiometer with scale), while the shoes, socks, and hats were removed. Weight was measured using a daily calibrated electronic scale (Ekoter mechanical stadiometer with scale), while the shoes, socks, and heavy garments were removed. The body mass index $\left(\mathrm{BMl} ; \mathrm{kg} / \mathrm{m}^{2}\right)$ was calculated using these measurements. To determine waist circumference, we located the upper hip bone and placed a measuring tape at the level of the uppermost part of the hipbone around the abdomen (ensuring that the tape measure was horizontal) and estimated at the end of expiration. The tape measure was snug but did not cause compressions on the skin. Blood pressure was recorded as the average of two measurements after subjects had been sitting for at least $5 \mathrm{~min}$.

MS was diagnosed in the presence of three or more criteria of the National Cholesterol Education Program's Adult Panel III. ${ }^{[14]}$ Waist circumference $>102 \mathrm{~cm}$ in men or $>88 \mathrm{~cm}$ in women; serum level of triglycerides (TGs) of $150 \mathrm{mg} /$ $\mathrm{dL}$ or greater; high-density lipoprotein (HDL) cholesterol level of $<40 \mathrm{mg} / \mathrm{dL}$ in men or $<50 \mathrm{mg} / \mathrm{dL}$ in women; systolic blood pressure (SBP)/diastolic blood pressure (DBP) of $130 / 85 \mathrm{mmHg}$ or greater or taking hypertension medications; or fasting plasma glucose level of $100 \mathrm{mg} / \mathrm{dL}$ or greater or taking diabetes mellitus medications.

Venous samples were taken at the enrolment visit after the subjects had fasted overnight (at least $8 \mathrm{~h}$ ). Plasma glucose was measured using a glucose oxidase method. Calcium, phosphorus, alanine transaminase, aspartate transaminase, gamma glutamyl transferase, alkaline phosphatase, albumin, serum cholesterol, and TG concentration by enzymatic colorimetric test, creatinine by Jaffe method, CRP by immunoassay, blood urea nitrogen by spectrophotometer, potassium, sodium, and chlorine level with ion-selective electrode analysis which was measured with Architect plus device. Hemogram parameters were measured with the Mindray MC6800 device by the electrical impedance method. T2DM was diagnosed according to the criteria American Diabetes Association. ${ }^{[15]}$

Transthoracic echocardiographic evaluation was performed according to the recommendations of the American Society of Echocardiography using the VIVID S6 (General Electric Vingmed Ultrasound Horten, Norway) echocardiography device capable of recording standard two-dimensional and $\mathrm{M}$-mode recording in the overall cardiology outpatient clinic. During echocardiographic evaluation, we measured epicardial fat thickness in the free wall of the right ventricle from both parasternal long- and short-axis views. Since the thickness of epicardial fat is not measured obliquely, we made our measurements in the longitudinal and transverse axis. ${ }^{[16-18]}$ EFTT was measured from a point perpendicular to the aortic annulus through 
the right ventricular free wall at the end of diastole during 3-4 cardiac cycles. ${ }^{[19]}$

All parameters were compared in two groups and the relationship between the longitudinal and transverse thicknesses of EFT and CRP and NLR was evaluated in both groups.

\section{Statistical Analysis}

Data were analyzed using MedCalc Statistical Software version 12.7.7 (MedCalc Software bvba, Ostend, Belgium; http://www.medcalc.org; 2013). Data were compared between two groups using the Student's $t$-test for continuous variables and $\mathrm{Chi}$-square tests for categorical variables. For correlations, Pearson's correlation test was used. $p<0.05$ was considered statistically significant.

\section{Results}

The general characteristics of the patients are summarized in Table 1. Anthropometric measurements such as weight, BMI, and waist circumference were significantly higher in the MS group ( $p=0.008, p=0.001$, and $p<0.001$, respectively). Both
SBP and DBP were statistically higher in MS patients $(p=0.007$ and $p=0.023$, respectively). Fasting glucose and TG levels were higher and HDL levels were lower in MS group $(p<0.001)$.

White blood cell (WBC) and neutrophil levels were higher in MS group ( $p=0.020$ and $p=0.019$, respectively). Transverse and longitudinal EFTT were found to be increased in MS patients (Table 1) $(p<0.001)$.

Transverse and longitudinal EFTT were higher in women and DM patients ( $p<0.05$, for both) (Table 2 ).

The correlations between the EFTT and other parameters are summarized in Table 3 in whole group. There was a significant positive correlation between transverse EFTT and age, weight, waist circumference, BMI, neutrophil count, NLR, and CRP. Significant positive correlations were found between longitudinal EFTT and weight, waist circumference, BMI, WBC, TG, neutrophil count, NLR, and CRP. There was a negative correlation between longitudinal EFTT and HDL (Table 3).

Comparisons of correlations between EFTT and CRP, neutrophil, and NLR in the patient and control groups are shown in Table 4. In the MS group, there was a significant

Table 1. Comparison of demographic, anthropometric, and clinical data between the patient and control groups

\begin{tabular}{|c|c|c|c|}
\hline & Patient group & Control group & $p$ \\
\hline Age (years) & $70.7 \pm 5.4$ & $70.2 \pm 5.3$ & 0.870 \\
\hline Gender (M [\%]/F [\%]) & $24(48) / 26(52)$ & $11(44) / 14(56)$ & 0.743 \\
\hline Weight (kg) & $80.6 \pm 13.0$ & $71.8 \pm 13.4$ & 0.008 \\
\hline Height (cm) & $156 \pm 10$ & $158 \pm 7$ & 0.202 \\
\hline Waist circumference $(\mathrm{cm})$ & $108.9 \pm 9.3$ & $97.4 \pm 12.4$ & $<0.001$ \\
\hline BMI $\left(\mathrm{kg} / \mathrm{m}^{2}\right)$ & $33.2 \pm 5.7$ & $28.4 \pm 5.1$ & 0.001 \\
\hline Diabetes mellitus ( $n$ [\%]) & $44(88)$ & $3(12)$ & $<0.001$ \\
\hline Hyperlipidemia ( $n$ [\%]) & $36(72)$ & $16(64)$ & 0.502 \\
\hline Hypertension ( $n$ [\%]) & $48(96)$ & $12(48)$ & $<0.001$ \\
\hline $\mathrm{SBP}(\mathrm{mm} / \mathrm{Hg})$ & $148.3 \pm 22.0$ & $136.3 \pm 21.2$ & 0.007 \\
\hline $\mathrm{DBP}(\mathrm{mm} / \mathrm{Hg})$ & $90.4 \pm 15.8$ & $84.4 \pm 18.3$ & 0.023 \\
\hline WBC $\left(/ \mathrm{mm}^{3}\right)$ & $7.3 \pm 1.6$ & $6.4 \pm 1.3$ & 0.020 \\
\hline Neutrophil $(10 \times \mu \mathrm{L})$ & $4.3 \pm 1.2$ & $3.6 \pm 1.1$ & 0.019 \\
\hline Lymphocyte (10 × $\mu \mathrm{L})$ & $2.2 \pm 0.7$ & $1.9 \pm 0.5$ & 0.057 \\
\hline NLR & $2.139 \pm 0.9$ & $2.0 \pm 0.7$ & 0.544 \\
\hline Hemoglobin (gr/dl) & $12.8 \pm 1.4$ & $13.3 \pm 0.8$ & 0.184 \\
\hline Glucose (mg/dL) & $139.2 \pm 60.6$ & $99.6 \pm 16.2$ & $<0.001$ \\
\hline TG $(\mathrm{mg} / \mathrm{dL})$ & 174.077 .5 & $104.8 \pm 35.6$ & $<0.001$ \\
\hline CRP (mg/dL) & $0.4 \pm 0.3$ & $0.4 \pm 0.6$ & 0.156 \\
\hline EFTT longitudinal (mm) & $5.9 \pm 1.7$ & $4.1 \pm 1.5$ & $<0.001$ \\
\hline EFTT transverse (mm) & $5.2 \pm 1.6$ & $3.7 \pm 1.4$ & $<0.001$ \\
\hline
\end{tabular}

BMI: Body mass index, CRP: C-reactive protein; DBP: Diastolic blood pressure; EFTT: Epicardial fat tissue thickness; NLR: Neutrophil-to-lymphocyte ratio; SBP: Systolic blood pressure;TG:Triglyceride,WBC:White blood cell. 
Table 2. Comparison of the mean values of EFTT according to gender, diabetes, hypertension, family history, and smoking

\begin{tabular}{|c|c|c|c|c|}
\hline & $\begin{array}{l}\text { Transverse } \\
\text { EFTT(mm) }\end{array}$ & $p$ & $\begin{array}{c}\text { Longitudinal } \\
\text { EFTT (mm) }\end{array}$ & $p$ \\
\hline Female & $5.3 \pm 1.8$ & 0.005 & $4.9 \pm 1.7$ & 0.036 \\
\hline Male & $4.2 \pm 1.4$ & & $5.9 \pm 2$ & \\
\hline DM (+) & $5.2 \pm 1.7$ & 0.002 & $5.9 \pm 1.8$ & 0.001 \\
\hline DM (-) & $4.0 \pm 1.5$ & & $4.4 \pm 1.8$ & \\
\hline$H L(+)$ & $4.7 \pm 1.6$ & 0.671 & $5.4 \pm 1.9$ & 0.745 \\
\hline HL (-) & $5.0 \pm 2.0$ & & $5.4 \pm 1.9$ & \\
\hline HT (+) & $4.8 \pm 1.8$ & 0.292 & $5.4 \pm 1.9$ & 0.766 \\
\hline HT (-) & $4.3 \pm 1.5$ & & $5.2 \pm 1.9$ & \\
\hline Smoking (+) & $4.4 \pm 1.9$ & 0.486 & $4.6 \pm 2.3$ & 0.163 \\
\hline Smoking (-) & $4.8 \pm 1.7$ & & $5.5 \pm 1.8$ & \\
\hline Family history (+) & $5.0 \pm 1.7$ & 0.308 & $5.8 \pm 1.8$ & 0.059 \\
\hline Family history (-) & $4.5 \pm 1.7$ & & $5.0 \pm 1.9$ & \\
\hline
\end{tabular}

DM: Diabetes mellitus; HL: Hyperlipidemia; HT: Hypertension; EFTT: Epicardial fat tissue thickness.

Table 3. The correlations between the EFTT and other parameters

\begin{tabular}{|c|c|c|c|c|}
\hline & \multicolumn{2}{|c|}{ Transverse EFTT } & \multicolumn{2}{|c|}{ Longitudinal EFTT } \\
\hline & $\mathbf{r}$ & $p$ & $\mathbf{r}$ & $p$ \\
\hline Age & 0.794 & $<0.001$ & -0.001 & 0.992 \\
\hline Weight & 0.273 & 0.018 & 0.291 & 0.011 \\
\hline Height & 0.007 & 0.953 & -0.049 & 0.673 \\
\hline Waist circumference & 0.269 & 0.019 & 0.364 & 0.001 \\
\hline BMI & 0.248 & 0.032 & 0.343 & $<0.001$ \\
\hline SBP & 0.109 & 0.354 & 0.007 & 0.952 \\
\hline DBP & 0.009 & 0.941 & -0.033 & 0.777 \\
\hline WBC & 0.218 & 0.060 & 0.214 & 0.065 \\
\hline Neutrophil & 0.375 & 0.001 & 0.393 & $<0.001$ \\
\hline Lymphocyte & -0.056 & 0.633 & -0.073 & 0.532 \\
\hline NLR & 0.374 & 0.001 & 0.371 & 0.001 \\
\hline FBG & 0.318 & 0.005 & 0.311 & 0.007 \\
\hline TG & 0.161 & 0.168 & 0.270 & 0.019 \\
\hline HDL & -0.215 & 0.083 & -0.238 & 0.040 \\
\hline CRP & 0.327 & 0.004 & 0.360 & 0.002 \\
\hline
\end{tabular}

BMI: Body mass index; CRP: C-reactive protein; DBP: Diastolic blood pressure; EFTT: Epicardial fat tissue thickness; FBG: Fasting blood glucose; NLR: Neutrophilto-lymphocyte ratio; SBP: Systolic blood pressure;TG:Triglyceride,WBC:White blood cell.

correlation between the longitudinal and transverse EFTT and neutrophil and NLR but not in the control group. In the control group, there was a significant positive correlation between longitudinal EFTT and CRP (Table 4).

\section{Discussion}

In this study, we found that there is a positive relationship between EFTT and NLR in MS patients over 65 years. No significant relationship was observed between EFTT and CRP. Both longitudinal and transverse EFTT are increased in MS patients over 65 years of age.

The MS has become an important health problem in the $21^{\text {st }}$ century with the increase in the average age of the world population. ${ }^{[20]}$ Three large meta-analyzes reported a 2 -fold increase in cardiovascular mortality, myocardial infarction, and stroke risk in patients with MS 
Table 4. The relationship between EFTT and CRP, neutrophil, NLR in the patient and control groups

\begin{tabular}{|c|c|c|c|c|c|}
\hline & \multirow[t]{2}{*}{ Group } & \multicolumn{2}{|c|}{ Transverse EFTT } & \multicolumn{2}{|c|}{ Longitudinal EFTT } \\
\hline & & $\mathbf{r}$ & $p$ & $\mathbf{r}$ & $p$ \\
\hline \multirow[t]{2}{*}{ CRP (mg/dL) } & Patient group & 0.198 & 0.169 & 0.226 & 0.114 \\
\hline & Control group & 0.304 & 0.139 & 0.441 & 0.028 \\
\hline \multirow[t]{2}{*}{ Neutrophil $(10 \times \mu \mathrm{L})$} & Patient group & 0.279 & 0.049 & 0.368 & 0.009 \\
\hline & Control group & 0.305 & 0.139 & 0.236 & 0.257 \\
\hline \multirow[t]{2}{*}{ NLR } & Patient group & 0.406 & 0.003 & 0.416 & 0.003 \\
\hline & Control group & 0.265 & 0.201 & 0.205 & 0.327 \\
\hline
\end{tabular}

CRP: C-reactive protein; EFTT: Epicardial fat tissue thickness; NLR: Neutrophil-to-lymphocyte ratio.

and a 1.5 -fold increase in all-cause mortality. ${ }^{[19]}$ It is also thought that MS has increased the risk of frailty in the elderly. ${ }^{[22]}$

Along with aging, there is a decrease in muscle mass and an increase in abdominal fat mass. EFT is closely related to intra-abdominal fat tissue as a predictor of whole-body visceral fat. In addition, there is a significant correlation between transthoracic echocardiographic measurements of EFT and intra-abdominal fat measured by MR. ${ }^{[23]}$ Because EFT is not affected by subcutaneous fat tissue, it is considered to be a good indicator of metabolic and cardiovascular risk associated with visceral fat. ${ }^{[1]}$

In a recent study, investigator showed that EFTT was higher in geriatric patients with MS. This has led to an increased interest in epicardial adipose tissue thickness. In the literature, an EFTT cutoff value for predicting MS in the geriatric patient group has not been established. In a study involving patients aged 22-65 years in Venezuela, it found that an EFTT level $>5 \mathrm{~mm}$ showed high sensitivity and specificity in predicting MS. ${ }^{[24]}$ In a study conducted in geriatric patients in Turkey; it has been shown that an EFTT level above $7.3 \mathrm{~mm}$ is indicative of MS with a sensitivity of $96.7 \% .{ }^{[25]}$ In this study by Kaya et al., EFTT was found to be an independent factor for MS in geriatric patients. ${ }^{[25]}$ In our study, both longitudinal and transverse measurements of EFTT were found to be higher in patients with MS older than 65 years. Our results were in concordance with the study conducted by Kaya et al. ${ }^{[25]}$ In the present study revealed that geriatric patients with MS had higher EFFT measured transversely and longitudinally. In addition, our study provided important new information and data revealing the cutoff levels of EFTT in geriatric patients with MS. We think that echocardiographic epicardial adipose tissue can be applied as an easy and reliable imaging indicator of cardiovascular risk.

In our study, mean EFTT values were $5.9 \mathrm{~mm}$ (transverse) and $5.2 \mathrm{~mm}$ (longitudinal) in MS group. We found a cutoff point of $3.6 \mathrm{~mm}$ for transverse EFTT and $5.2 \mathrm{~mm}$ for longitudinal EFTT in predicting MS using ROC curves, but we could not define a cutoff point for NLR. Especially patients with diabetes mellitus had higher EFTT values.

The previous studies have reported a relationship between EFTT and MS and cardiovascular risk factors. ${ }^{[26,27]}$ Epicardial adipose tissue is metabolically active and secretes some adipokines and inflammatory cytokines. ${ }^{[28,29]}$

WBC count and CRP are independent predictors of allcause mortality and cardiovascular mortality. In recent years, an index that reflects both increase in neutrophil count demonstrating acute state of inflammation, and the lymphopenia occurs after acute physiological stress has begun to be used. ${ }^{[30]}$ This index, called NLR, was used in studies with other inflammatory markers and was found to be a good indicator of inflammatory status. NLR has been described as a potential systemic inflammatory marker. NLR has been shown to be an independent prognostic factor for several cancers and cardiovascular diseases. ${ }^{[31-33]}$ Besides; NLR is associated with morbidity and mortality in diabetics. ${ }^{[11]}$ In addition, it is correlated with MS among Asian Indians. ${ }^{[13]}$ NLR is inexpensive, easy to reach, and calculate. It is obtained from complete blood count. ${ }^{[34]}$ Shiny et al. reported that NLR is related with glucose intolerance and insulin resistance and can be helpful in determining micro- and macrovascular complications in patients with glucose intolerance. ${ }^{[35]}$ In this study, WBC and neutrophil levels were significantly higher in the MS group and this difference was not observed for CRP. Correlation analysis showed a moderate positive correlation between EFTT and NLR in the MS group indicating that NLR may be a good indicator of visceral fat tissue surrounding myocardium in the elderly.

Jung et $a .^{[36]}$ investigated the correlation between WBC count and MS in Korean and in normal WBC cases and 
without significant medical illness history, BMI and TG were significantly associated with WBC levels. They were also found to be the earliest components of MS in postmenopausal women and men. In a study of Mazidi et al., CRP levels in MS patients were significantly higher. However, in our study, CRP levels were not different from those without MS. ${ }^{[37]}$

Our findings support that the increase in EFT may be associated with an increase in systemic inflammatory burden, and that these parameters may be used as MS markers.

\section{Conclusion}

Our study showed that both longitudinal and transverse EFTT are associated with NLR in patients older than 65 years with MS. In the MS patients older than 65 years, NLR is closely related to EFT. In older MS patients, higher NLR level may be a good indicator of increased visceral fat around the myocardium. There is no association between CRP and EFTT in patients older than 65 years with MS. These findings suggest that NLR is a better predictor of EFTT compared to CRP in older MS patients.

\section{Disclosures}

Ethics Committee Approval: The Ethics Committee of University of Health Sciences Umraniye Education and Research Hospital, Date: 15.12.2016; Number: B.10.1.TKH.4.34.H.GP.0.01/128.

Peer-review: Externally peer-reviewed.

Conflict of Interest: None declared.

Authorship Contributions: Concept - G.U., S.U.B.; Design - G.U., S.U.B.; Supervision - S.U.B., O.B.; Materials - G.U.; Data collection \&/or processing - G.U., A.N.C.; Analysis and/or interpretation G.U., R.S.; Literature search - G.U.; Writing - G.U., R.S.; Critical review - S.U.B., O.B.

\section{References}

1. Villasante Fricke AC, lacobellis G. Epicardial adipose tissue: clinical biomarker of cardio-metabolic risk. Int J Mol Sci 2019;20:5989. [CrossRef]

2. Monti CB, Codari M, De Cecco CN, Secchi F, Sardanelli F, Stillman AE. Novel imaging biomarkers: epicardial adipose tissue evaluation. Br J Radiol 2020;93:20190770. [CrossRef]

3. Gandoy-Fieiras N, Gonzalez-Juanatey JR, Eiras S. Myocardium metabolism in physiological and pathophysiological states: implications of epicardial adipose tissue and potential therapeutic targets. Int J Mol Sci 2020;21:2641. [CrossRef]

4. Katsiki N, Stoian AP, Steiropoulos P, Papanas N, Suceveanu AI, Mikhailidis DP. Metabolic syndrome and abnormal peri-organ or intra-organ fat (APIFat) deposition in chronic obstructive pulmonary disease: an overview. Metabolites 2020;10:465. [CrossRef]
5. Balcioğlu AS, Durakoğlugil ME, Ciçek $D, B a l$ UA, Boyaci $B$, Müderrisoğlu H. Epicardial adipose tissue thickness and plasma homocysteine in patients with metabolic syndrome and normal coronary arteries. Diabetol Metab Syndr 2014;6:62. [CrossRef]

6. Jo EA, Cho KI, Park JJ, Im DS, Choi JH, Kim BJ. Effects of highintensity interval training versus moderate-intensity continuous training on epicardial fat thickness and endothelial function in hypertensive metabolic syndrome. Metab Syndr Relat Disord 2020;18:96-102. [CrossRef]

7. Avan A, Tavakoly Sany SB, Ghayour-Mobarhan M, Rahimi HR, Tajfard M, Ferns G. Serum C-reactive protein in the prediction of cardiovascular diseases: Overview of the latest clinical studies and public health practice. J Cell Physiol. 2018;233:8508-25. [CrossRef]

8. Başer M, Özgür R, Mavi, O, Özdemir AA, Özkeskin A, Küçükdemirci Ö, et al. The relationship of hs-CRP with regulation of hypertension in patients who have both Type 2 diabetes mellitus and hypertension. Sisli Etfal Hastan Tip Bul 2014;48:182-7. [CrossRef]

9. Zhang X, Cui L, Chen B, Xiong Q, Zhan Y, Ye J, et al. Effect of chromium supplementation on hs-CRP, TNF- $a$ and IL- 6 as risk factor for cardiovascular diseases: A meta-analysis of randomized-controlled trials. Complement Ther Clin Pract 2021;42:101291. [CrossRef]

10. Atılgan CÜ, Şendül SY, Kösekahya P, Çağlayan M, Alkan A, Güven $D$, et al. Evaluation of neutrophil-to-lymphocyte ratio and mean platelet volume in patients with active and inactive thyroid orbitopathy. Sisli Etfal Hastan Tip Bul 2018;52:26-30.

11. Wan $H$, Wang $Y$, Fang $S$, Chen $Y$, Zhang W, Xia F, et al. Associations between the neutrophil-to-lymphocyte ratio and diabetic complications in adults with diabetes: a cross-sectional study. J Diabetes Res 2020;2020:6219545. [CrossRef]

12. Delcea C, Buzea CA, Dan GA. The neutrophil to lymphocyte ratio in heart failure: a comprehensive review. Rom J Intern Med 2019;57:296-314. [CrossRef]

13. Surendar J, Indulekha K, Mohan V, Pradeepa R. Association of neutrophil-lymphocyte ratio with metabolic syndrome and its components in Asian Indians (CURES-143). J Diabetes Complications 2016;30:1525-9. [CrossRef]

14. National Cholesterol Education Program (NCEP) Expert Panel on Detection, Evaluation, and Treatment of High Blood Cholesterol in Adults (Adult Treatment Panel III). Third Report of the National Cholesterol Education Program (NCEP) Expert Panel on Detection, Evaluation, and Treatment of High Blood Cholesterol in Adults (Adult Treatment Panel III) final report. Circulation 2002;106:3143-421. [CrossRef]

15. American Diabetes Association. 2. classification and diagnosis of diabetes: standards of medical care in diabetes-2021. Diabetes Care 2021;44:S15-33. [CrossRef]

16. Schejbal V. Epicardial fatty tissue of the right ventricle-morphology, morphometry and functional significance. [Article in German]. Pneumologie 1989;43:490-9. 
17. Bertaso AG, Bertol D, Duncan BB, Foppa M. Epicardial fat: definition, measurements and systematic review of main outcomes. Arq Bras Cardiol 2013;101:e18-28. [CrossRef]

18. lacobellis G, Ribaudo MC, Assael F,Vecci E, Tiberti C, Zappaterreno A, et al. Echocardiographic epicardial adipose tissue is related to anthropometric and clinical parameters of metabolic syndrome: a new indicator of cardiovascular risk. J Clin Endocrinol Metab 2003;88:5163-8. [CrossRef]

19. lacobellis G, Sharma AM. Epicardial adipose tissue as new cardio-metabolic risk marker and potential therapeutic target in the metabolic syndrome. Curr Pharm Des 2007;13:2180-4. [CrossRef]

20. Fiuza M, Cortez-Dias N, Martins S, Belo A; VALSIM study investigators. Metabolic syndrome in Portugal: prevalence and implications for cardiovascular risk-results from the VALSIM Study. Rev Port Cardiol 2008;27:1495-529.

21. Galassi A,ReynoldsK,HeJ.Metabolicsyndromeandriskofcardiovascular disease: a meta-analysis. Am J Med 2006;119:812-9. [CrossRef]

22. Viscogliosi $G$. The metabolic syndrome: a risk factor for the frailty syndrome? J Am Med Dir Assoc 2016;17:364-6. [CrossRef]

23. lacobellis G, Willens HJ. Echocardiographic epicardial fat: a review of research and clinical applications. J Am Soc Echocardiogr 2009;22:1311-9. [CrossRef]

24. Lima-Martínez MM, Paoli M, Donis JH, Odreman R, Torres C, lacobellis $\mathrm{G}$. Cut-off point of epicardial adipose tissue thickness for predicting metabolic syndrome in Venezuelan population. [Article in Spanish]. Endocrinol Nutr 2013;60:570-6. [CrossRef]

25. Kaya B, Kaya BC, Karakas EY, Baysal SS, Cadirci D, Erkus E, et al. Usefulness of the epicardial fat tissue thickness as a diagnostic criterion for geriatric patients with metabolic syndrome. J Geriatr Cardiol 2015;12:373-7.

26. Cho Kl, Jo EA, Cho SH, Kim BH. The influence of epicardial fat and nonalcoholic fatty liver disease on heart rate recovery in metabolic syndrome. Metab Syndr Relat Disord 2017;15:226-32. [CrossRef]

27. Bachar GN, Dicker D, Kornowski R, Atar E. Epicardial adipose tissue as a predictor of coronary artery disease in asymptomatic subjects. Am J Cardiol 2012;110:534-8. [CrossRef]

28. Gruzdeva OV, Borodkina AD, Akbasheva OE, Dileva YA, Antonova LV, Matveeva VG, et al. Influence of visceral obesity on the secretion of adipokines with epicardial adipocytes in patients with coronary heart disease. Ter Arkh 2018;90:71-8. [CrossRef]

29. Gruzdeva OV, Akbasheva OE, Dyleva YA, Antonova LV, Matveeva VG, Uchasova EG, et al. Adipokine and cytokine profiles of epicardial and subcutaneous adipose tissue in patients with coronary heart disease. Bull Exp Biol Med 2017;163:608-11. [CrossRef]

30. Liu J, Li S, Zhang S, Liu Y, Ma L, Zhu J, et al. Systemic immune-inflammation index, neutrophil-to-lymphocyte ratio, platelet-to-lymphocyte ratio can predict clinical outcomes in patients with metastatic non-small-cell lung cancer treated with nivolumab. J Clin Lab Anal 2019;33:e22964. [CrossRef]

31. Williams KA, Labidi-Galy SI, Terry KL, Vitonis AF, Welch WR, Goodman A, et al. Prognostic significance and predictors of the neutrophil-to-lymphocyte ratio in ovarian cancer. Gynecol Oncol 2014;132:542-50. [CrossRef]

32. Stotz M, Gerger A, Eisner F, Szkandera J, Loibner H, Ress AL, et al. Increased neutrophil-lymphocyte ratio is a poor prognostic factor in patients with primary operable and inoperable pancreatic cancer. Br J Cancer 2013;109:416-21. [CrossRef]

33. Guasti L, Dentali F, Castiglioni L, Maroni L, Marino F, Squizzato A, et al. Neutrophils and clinical outcomes in patients with acute coronary syndromes and/or cardiac revascularisation. A systematic review on more than 34,000 subjects. Thromb Haemost 2011;106:591-9. [CrossRef]

34. Bhat T, Teli S, Rijal J, Bhat H, Raza M, Khoueiry G, et al. Neutrophil to lymphocyte ratio and cardiovascular diseases: a review. Expert Rev Cardiovasc Ther 2013;11:55-9. [CrossRef]

35. Shiny A, Bibin YS, Shanthirani CS, Regin BS, Anjana RM, Balasubramanyam $M$, et al. Association of neutrophil-lymphocyte ratio with glucose intolerance: an indicator of systemic inflammation in patients with type 2 diabetes. Diabetes Technol Ther 2014;16:524-30. [CrossRef]

36. Jung CH, Lee WY, Kim BY, Park SE, Rhee EJ, Park CY, et al. The risk of metabolic syndrome according to the white blood cell count in apparently healthy Korean adults. Yonsei Med J 2013;54:61520. [CrossRef]

37. Mazidi M, Toth PP, Banach M. C-reactive protein is associated with prevalence of the metabolic syndrome, hypertension, and diabetes mellitus in US adults. Angiology 2018;69:438-42. [CrossRef] 